Invited Paper

\title{
Capillary Electrophoresis Separation Techniques and Mechanisms in Dilute Polymer Matrices
}

\author{
Michael J. Navin and Michael D. Morris* \\ Department of Chemistry, The University of Michigan, $930 \mathrm{~N}$. University Avenue, Ann Arbor, \\ MI, 48109-1055, U.S.A.
}

\begin{abstract}
Capillary electrophoresis in ultradilute derivatized solutions is used to separate mucleic acid fragment mixtures. Pulsed field techniques are used to improve resolution. Protocols in which pulse parameters are varied during the course of the separation are used to increase the range of fragment sizes separated. Fluorescence microscopy is used to study the separation mechanism in ultradilute solution.
\end{abstract}

\section{INTRODUCTION}

Interest in capillary elcctrophoresis has grown dramatically over the past few years. Sweeping advances have been made in many different areas of the technique such as instrumental and method development research including improved detection schemes, ${ }^{[-4}$ investigation into separation mechanisms, and use of capillary arrays ${ }^{6-8}$ to decrease analysis time. Progress on the experimental side of capillary electrophoresis is winning ever-widening roles in molecular biology, biochemistry and other ficlds.

Recently, our group has been exploring techniques for separations of long chain nucleic acid fragments by capillary electrophoresis in linear polymer matrices. To this end, we are investigating the use of ultradilute matrices and electric field modulation ${ }^{9-11}$ to increase fragment mobilities while improving resolution. Additionally, we are performing direct DNA imaging expenments, which allow the observation of DNA behavior under different separation conditions. Finally, intracapillary Raman thermometry has been used to measure temperature distributions of Joule heating caused inside a capillary during electrophoresis. ${ }^{12}$ The temperature studies have guided investigations into the effects of heating on fragment mobilities and resolution during electrophoresis, ${ }^{10}$ and have led to instrumentation for efficient dissipation of this energy.

\section{Capillary Electrophoresis in Dilute Polymer Matrices}

Agarose slab gel electrophoresis has been used for nucleic acid separations for many years. The cross-linked matrix is employed for its sieving properties, which are essential for nucleic acid and protein separations. ${ }^{13}$ The limiting time factor for slab gel electrophoresis is the very low electric field that can be applied. Joule heating that results from high electric tields will lead to sample degradation, gel failures, and band broadening. Capillary gel electrophoresis (CGE) was developed to take advantage of the superior heat dissipation characteristics of narrow bore capillaries ${ }^{14}$ and thus allow the use of high fields, which leads to faster and more efficient separations.

The pioneering capillary gel electrophoresis by Heiger et. $a .^{15}$ and our initial efforts in pulsed field $\mathrm{CGE}^{16}$ were performed in cross-linked polyacrylamide gel matrices. The use of cross-linked polyacrylamide followed naturally from the success of agarose slab gel matrices. The tcchnique worked very well for protein and short chain nucleic acid separations. These capillary separations had high resoIntion and were completed in a fraction of the time of the corresponding slab gel separations.

Drawbacks of the cross-linked matrices are that they must be prepared inside the capillary and they are not very reproducible. In addition, during the course of a separation the stresses placed on the gel matrix cause damage in the matrix, reducing the lifetime of the capillary. ${ }^{17}$ Linear polymers were found to be equally useful separation matrices for nucleic acids and are much easier to use than the crosslinked polymers. ${ }^{18-28}$ Water soluble derivatized celluloses are commercially available and the sieving buffers are easy to prepare reproducibly. The solution viscosities are lower than cross-linked gels, so the separations are more rapid. We have shown that hydroxyethyl cellulose concentration about $0.05 \%$ ( $w / w$ ) is near optimum for restriction enzyme fragment separations ${ }^{9}$ and Barron $e$ l. $a{ }^{18}{ }^{18}$ also found that dilute linear polymers give good separations.

Surprisingly, baseline resolved separations are obtained even if the polymer concentration is reduced well below down the entanglement limit. Barron et. al. ${ }^{18.29}$ and Kim and Morris ${ }^{10}$ independently reported that hydroxyethyl cel- 
lulose at a concentration of $0.002 \%(\mathrm{w} / \mathrm{w})$ in $1 \mathrm{X}$ TBE gives good separations of $\lambda$ DNA/HindlII restriction enzyme fragments. Theories based on established polymer solution physics predict that DNA separations should not be possible in these dilute matrices. The theories require interaction between DNA and a fully entangled matrix. ${ }^{30-35}$ For the celluloses employed, the entanglement limit is about $0.1 \%$. Subentanglement celluJose solutions have viscosities only slightly greater than aqueous solutions, yielding very rapid separations. For example, in Fig. 1 we show completely resolved $\lambda$ DNA $/ H i n d I I$ restriction enzyme fragments separated in less than 10 minutes in $0.015 \%$ methy] cellulose, using field modulation. This time is much shorter than required in a gel-filled capillary (20-40 min.), and a major improvement over the hour or more necessary in the conventional slab gel electrophoresis.

Multi Frequency Pulsed Field Capillary Electrophoresis

An instrumental technique which shows promise for rapid and efficient DNA separations is the implementation of field modulation in capillary clectrophoresis. Pulsed field techniques have been used in slab gel electrophoresis

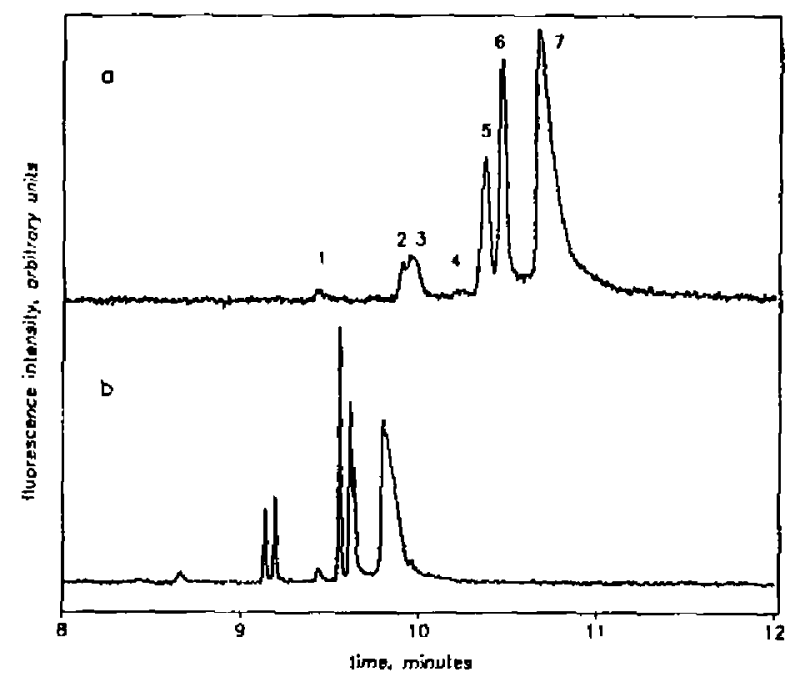

Fig. 1. Electrophoretic separation of $\lambda D N A / H i n d l 1$ digest in $0.015 \%(w / w)$ methyl cellulose in $1 \mathrm{X}$ TBE. Capillary dimensions: $75 \mu \mathrm{m}$ i.d., $365 \mu \mathrm{m}$ o.t.; $33.0 \mathrm{~cm}$ long, with $28.5 \mathrm{~cm}$ from inlet to detection window. Sample: $12 \mathrm{ng} / \mathrm{\mu l}$ in $1 \mathrm{X}$ TBE; electrokinetic injection, $0.7 \mathrm{kV}$ for $4 \mathrm{~s}$. Detection: laser induced fluorescence of DNA/ ethidium bromide $(3 \mathrm{ng} / \mu \mathrm{l})$ complex. Separation fields: (a) $-180 \mathrm{~V} / \mathrm{cm} \mathrm{DC,} \mathrm{(b)}-180 \mathrm{~V} / \mathrm{cm} \mathrm{DC,} 252$ $\mathrm{V} / \mathrm{cm} \mathrm{AC}$ with $1 \mathrm{KHz}$ sine wave modulation. Peak legend: $1=554,2=2028,3=2322,4=$ $4371,5=6657,6=9419,7=23130$ base pairs. for ten years. Theoretical studies and computer simulations have predicted that by disrupting the electric field the alignment of the DNA molecule is also interrupted, allowing for size based separations. ${ }^{36-40}$ In addition, the jostling brought about by the field modulation frees any trapped DNA molecules, eliminating the mobility minimum observed for very large nucleic acids. Rampino and Chrambach ${ }^{41.42}$ and Holzwarth et. al. ${ }^{43-45}$ have verified these motions by fluorescence microscopy.

Early work by Heiger et. al. ${ }^{15}$ demonstrated resolution enhancement by field inversion capillary gel electrophoresis. The effects of modulation depth and frequency were investigated by our group ${ }^{16}$ which introduced sinusoidal modulation. We showed that the use of single frequency, single amplitude sine waves to modulate the field resulted in separation enhancement for one specific size range of DNA fragments. Novotny et. al. have recently extended field modulation techniques to the separation of polysaccharides $^{46}$ and charged polystyrene spheres, ${ }^{5}$ illustrating the effects of pulsed fields on samples much smaller than kilobase-sized nucleic acid fragments.

Based on these findings and building on the work of Noolandi in slab gels, ${ }^{47}$ we have recently developed variable frequency sinusoidal modulation protocols for field inversion CGE." Because there is generally a wide range of fragment sizes in one separation mixture, a variable frequency protocol provides optimum separation conditions for the entire fragment mixture during one separation. We found that the net mobilities are primarily a function of the overall applied field, almost independent of the modulation frequencies. However, the resolution is directly dependent on the frequency range of the putse protocol.

We have been developing more sophisticated pulse protocols in which both the field amplitude and the frequency are varied. By starting the modulation after the smaller fragments in a mixture have eluted, we are able to observe the small fragment resolution found under DC conditions, as well as the large fragment resolution which requires modulation. ${ }^{10}$ We vary both the field strengths and modulation frequencies to now achieve rapid separations of fragments ranging from 70-23,000 base pairs in length. For example, Fig. 2 shows the separation achieved by increasing the $\mathrm{AC}$ field strength from $100 \%$ of $\mathrm{DC}$ to $140 \%$ during the course of the separation after a short DC only period achieves complete separation of a fragment mixture ranging from 75 to 12216 base pairs. By using of dynamic pulse protocols during an electrophoretic separation, the separated fragment size range can be extended far beyond the present limits of $D C$ electrophoresis. 


\section{DNA Fhorescence Imaging}

We are supplementing our electrophoretic studies with fluorescence microscopic investigations of DNA migration. The technique was introduced by Smith et. al. ${ }^{48}$ and extended by Rampino and Chrambach ${ }^{41,42}$ and Holzwarth $e$. $a l^{43-45}$ for various agarose slab gel electrophoresis conditions. Perkins et. al. ${ }^{49}$ have recently looked at the DNA motions under field-free conditions by immobilizing a bead to one end of a nucleic acid molecule and dragging it through a matrix with optical tweezers. This work provides insight into the DNA migration characteristics and reorientation mechanics in gels and fully entangled polymers, but not under the conditions in dilute polymer solutions near and below entanglement concentrations.

Our images show that indeed the basics of entanglement theories are valid. The DNA appears to become entangled at one point along its length forming a U- or V-shaped

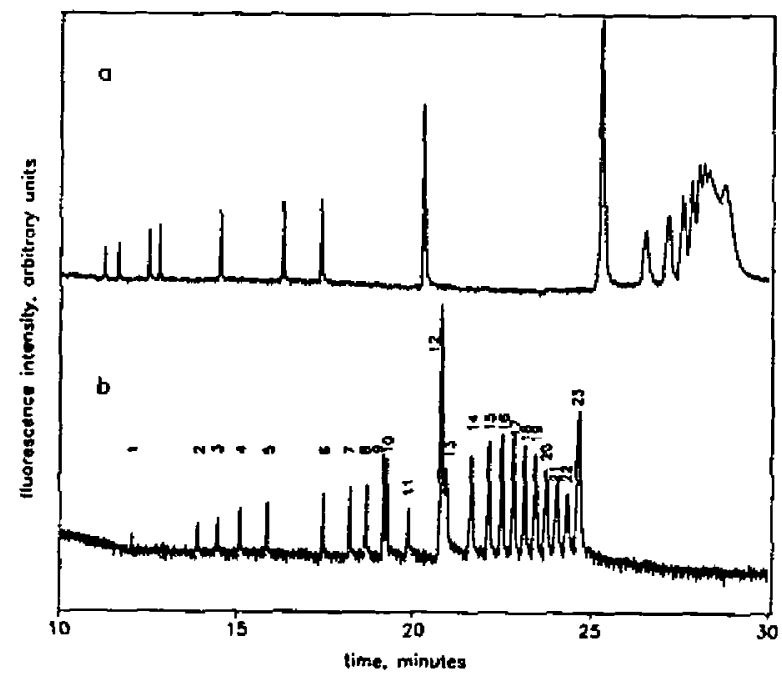

Fig. 2. Electrophoretic separation of $1 \mathrm{~kb}$ ladder digest in $7.5 \% \mathrm{~T}$ lincar polyacrylamide in $1 \mathrm{X} \mathrm{TBE}$, Capillary dimensions: $75 \mu \mathrm{m}$ i.d., $365 \mu \mathrm{m}$ o.d.; $20.0 \mathrm{~cm}$ long, with $15.0 \mathrm{~cm}$ from inlet to detection window. Sample: $55 \mathrm{ng} / \mu$ in $1 \mathrm{X}$ TBE; electrokinetic injection, $2 \mathrm{kV}$ for $2.5 \mathrm{~s}$. Detection: laser induced fluorescence of DNA/propidium iodide ( $2 \mathrm{ng} / \mu \mathrm{l})$ complex. Separation fields: (a) $250 \mathrm{~V} / \mathrm{cm} \mathrm{DC}$, (b) $-250 \mathrm{~V} / \mathrm{cm}$ DC for $6 \mathrm{~min}$, followed by $350 \mathrm{~V} / \mathrm{cm} \mathrm{AC}$ for $14 \mathrm{~min} ., 250 \mathrm{~V} / \mathrm{cm}$ $\mathrm{AC}$ for $2 \mathrm{~min}$, and $350 \mathrm{~V} / \mathrm{cm} \mathrm{AC}$ for $8 \mathrm{~min}$. The modulation protocol was random frequency square waves between $5-100 \mathrm{~Hz}$ with a 1 cycle dwell at each frequency. Peak legend: $1=75,2=$ $142,3=154,4=200,5=220,6=298,7=344$, $8=394,9=506,10=516,11=1018,12=1635$, $13=2036,14=3054,15=4072.16=5090,17=$ 6108. $18=7126,19=8144,20=9162,21=$ $10180,22=11198,23=12216$ base pairs. conformation (Fig. 3a). This is in contrast to entanglement at many discrete points along the backbone of the molecule, which has been observed in agarose $e^{41.42}$ and postulated by Barron et. al. in the dilute matrices. ${ }^{29}$ Additionally, this point of entanglement remains almost stationary in matrices whose concentrations are well above the entanglement limit of the polymer. The entanglement point migrates in the direction of the electric field in matrices near or more dilute than the cellulose entanglement concentration (Fig. 3b). As most theories of gel electrophoresis predict, separation occurs under conditions where an irregular DNA conformation can be generated. The surprise is that an entangled matrix is not needed to produce this conformation.

This dynamic entanglement between the DNA and the matrix allows for such techniques as field modulation to be useful for ultradilute polymer solutions in capillary clectrophoresis, as we have demonstrated. We are now beginning to use imaging to study migration under pulsed fields. We expect to observe the perturbations in DNA motions caused by field reversal and to estahlish what field strengths and frequencies would be optimum for a given size range.

\section{Intracapillary Temperature Studies}

Our interest in intracapillary temperatures derives from our lield modulation work. The imposed modulation increases power dissipation in the capillary, thus increasing temperature and mobility. As we have reported, in field inversion electrophoresis the heat generated by higher electric fields results in faster fragment mobilities. But resolution is reduces in isorheic DC elcctrophoresis. "

Theoretical calculations by Bello and Righetti ${ }^{50,51}$ and Gobie and Ivory ${ }^{52}$ predict an average temperature increase inside the capillary as a consequence of the current flow. We have used Raman thermometry to measure intracapillary temperatures ${ }^{12}$ and compare them to predictions and exist-

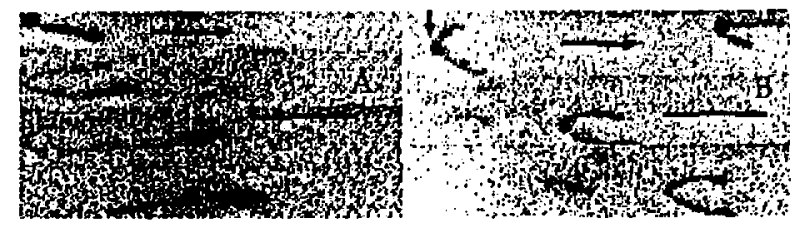

Fig. 3. Time sequence images of yeast chromosomal DNA. The migradon direction is indicated by the arrows, and the scale bars represent $10 \mu \mathrm{m}$. Electrophoretic conditions: (a) $0.5 \%$ hydroxyethyl cellulose in $50 \%$ sucrose and $0.5 \mathrm{X} \mathrm{TBE}, 25 \mathrm{~V} / \mathrm{cm}$ DC field. The images are at $16.0 \mathrm{~s}$ intervals. (b) $0.16 \%$ hydroxyethyl cellulose in $55 \%$ sucrose and $0.5 \mathrm{X}$ TBE, $25 \mathrm{~V} / \mathrm{cm}$ DC field. The images are at $8.0 \mathrm{~s}$ intervals. 
ing theories. ${ }^{53}$ We have found that the theories are fundamentally correct, but there are discrepancies between predictions and actual measurements. The discrepancies are caused by the use of unrealistic boundary conditions in the calculations. The most important of these is the neglect of the heat sinks created in fastening the capillary to external supports. The heat sinks cause substantial themal gradients along the length of the capillary, which affect the average temperature, and more importantly, are a source of band broadening.

Presently there are two practical ways of dissipating the heat generated by the electric fields. One is by active convective cooling (i.e. blowing air over the capillary) and the other is by flowing a liquid around the capillary housing. We prefer to the first method because if it is by far the simpler to implement. We have developed a simple and effective solid statc system to remove the heat from the capillary and have been able to bandle fields up to $1300 \mathrm{~V} / \mathrm{cm}$ without an appreciable temperature increase. The capillary is enclosed in a metallic heat sink with a thin ceramic layer in contact with the capillary itself. The large area of the heat sink allows very efficient convective cooling and the ceramic functions as an electrical insulator. This should allow for DNA separations at higher electric fields without the thermal degradation of the sample and matrix during the electrophoresis ind without deleterious resolution effects.

\section{ACKNOWLEDGMENT}

This work has been supported in part by the National Institutes of Health through Grant GM-37006. We would like to thank Richard W. Hammond, Yongseong Kim, Tracey L. Rapp, and $X_{\text {utelong }}$ Shi for their valuable input.

Received August 30, 1994.

\section{Key Words}

Capillary electrophoresis; Nucleic acid; DNA; Mechanisms; Gel; Sieving buffer.

\section{REFERENCES}

I. Swerdlow, H.; Zhang, J-Z; Chen, D-Y; Harke, H. R.; Grey, R.; Wu, S.; Dovichi, N. D.; Fuller, C. Anal. Chem. 1991, 63, 2335-284I.

2. Figeys, D.; Arriaga, E; Renborg, A.; Dovichi, N. J. J. Chromatogr. A, 1994, 669, 205-216.
3. Chang, H-T.; Yeung, E. S. Anal. Chem. 1993, 65, 2947 2951.

4. Dadoo, R.; Seto, A. G.; Colón, L. A.; Zare, R. N. Anal. Chem. 1994, 66, 303-306.

5. Sudor, J.; Novotony, M. V. Anal. Chem. 1994, 66, 2139 2147.

6. Huang, X. C.; Quesada, M. A.; Mathies, R. A. Anal. Chem. 1992, 64, 2149-2154.

7. Clark, S. M.; Mathies, R. A. Anal. Biochem. 1993, 215, 163-170.

8. Ueno, K.; Yeung, E. S. Anal. Chem. 1994, 66, 1424 1431.

9. Kim, Y.; Morris, M. D. Anal. Chem. 1994, 66, 1168 1174.

10. Kim, Y.; Morris, M. D. Anal. Chem. 1994, 66, 30813085.

11.Navin, M. J.; Rapp, T. L.; Morris, M. D. Anal. Chem. 1994, 66, 1179-1182.

12. Davis, K. L.; Liu, K-L. K.; Lanan, M.; Morris, M. D. Anal. Chem. 1993, 65, 293-298.

13. deGennes, P. G. Scaling Concepts in Polymer Physics Cornell University Press, Ithaca, NY, 1979.

14. Hjertén, S. J. J. Chromatogr. 1985, 347, 191-198.

15. Heiger, D. N.; Cohen, A. S.; Karger, B. L. J. Chromatogr. 1990, 516, 33-48.

16. Demana, T.; Lanan, M.; Morris, M. D. Anal. Chem. 1991, 63, 2795-2797.

17. Karger, A. E.; Harris, J. M.; Gesteland, R. F. Nucleic ACids Research 1991, 19, 4955-4962.

18. Barron, A. E.; Soane, D. S.; Blanch, H. W. J. Chromatogr. 1993, 652, 3-16.

19. Izumi, T.; Yamaguchi, M.; Yoneda, K.; lsobe, T.; Okuyama, T.; Shinoda, T. J. Chromatogr. 1993, 652, 4146.

20. Ganzler, K.; Greve, K. S.; Cohen, A. S.; Karger, B. L.; Guttman, A.; Cooke, N. C. Anal. Chem. 1992, 64, 26652671.

21. Chrambach, A.; Aldroubi, A. Electrophoresis 1993, 14, 18-22.

22. Paulus, A.; Husken, D. Electrophoresis 1993, 14, 27-35.

23. Chiari, M.; Nesi, M.; Righetti, P. G. J. Chromatogr. 1993, 652, 31-39.

24. Schwartz, H. E.; Ulfelder, K.; Sunzeri, F. J.; Busch, $M$. P.; Brownlee, R. G. J. Chromatogr. 1991, 559, 267-283.

25. Strege, M.; Lagu, A. Anal. Chem. 1991, 63, 1233-1236.

26. Grossman, P. D.; Soane, D. S. J. Chromatogr. 1991, 559, 257-266.

27. Kleemis, M. H.; Gigles, M.; Schomburg, G. Electrophoresis 1993, 14, 515-522.

28. Singhal, R. P.; Xian, J. J. Chromatogr. 1993, 652, 47-56. 
29. Barron, A. E.; Blanch, H. W.; Soane, D. S. Electrophoresis 1994, 15, 597-615.

30. Ogston, A. G. Trans. Faraday Soc. 1958, 54, 17541757.

31. Rodbard, D.; Chrambach, A. Proc. Nat. Acad. Sci. U. S. A. 1970, 65, 970-977.

32. Chrambach, A.; Rodbard, D. Science 1971, I70, 440451.

33. Rodbard, D.; Chrambach, A. Anal. Biochem. 1971, 40, 95-134.

34. Slater G. W.; Rousseau, J.; Noolanđi, J.; Tunnel, C.; Lalande, M. Biopolymers 1988, 27, 509-524.

35. Viovy, J. L.; Duke, T.; Caron, F. Contemporary Physics 1992, 33, 25-40.

36. Slater, G. W.; Noolandi, J. Biopolymers 1986, 25, 413 454.

37. Slater, G. W; Rousseau, J.; Noolandi, J. Biopolymers 1987, 26, 863-872.

38.Zimm, B. H.; Lumpkin, O. Macromolecules 1993, 26, 226-234

39. Chu, G. Proc. Natl. Acad. Sci. U. S. A. 1991, 31, 13971307.

40. Lumpkin, O. J.; Déjardin, P.; Zimm, B. H. Biopolymers $1985,24,1573-1593$.

41. Rampino, N. J.; Chrambach, A. J. Chromatogr: 1992, $596,141-149$.
42. Rampino, N. J.; Chrambach, A. Biopolymers 1991, 3I, 1297-1307.

43. Holzwarth, G.; McKee, C. B.; Steiger, S.; Crater, G. D. Nucleic Acids Res. 1987, 15, 10031-10044.

44. Keiner, L. E.; Holzwarth, G. J. Chem. Phys. 1992, 97, 4476-4484.

45. Crater, G. D.; Gregg, M. R., Holzwarth, G. Electrophoresis $1989,10,310-315$.

46. Sudor, J.; Novotony, M. Proc. Natl. Acad. Sci. U. S. A. 1993, $90,9451-9455$.

47. Noolandi, J. Ann. Rev. Phys. Chem. 1992, 43, 237-256.

48. Smith, S. B.; Aldridge, P. K.; Callis, J. B. Science 1989, 243, 203-206.

49. Perkins, 'T. T.; Smith, D. E.; Chu, S. Science 1994, 264, 819-826.

50. Bello, M. S.; Righett, P. G. J. Chromatogr. 1992, 606, 95-102.

51. Belio, M. S.; Righetti, P. G. J. Chromatogr. 1992, 606, 108-111.

52. Gobie, W. A.; Ivory, C. F. J. Chromatogr. 1990, 5I6, 191-210.

53. Liu, K-L. K.; Davis, K. L.; Morris, M. D. Anal. Chem. 1994, 66, in press.

54. Nelson, R. J.; Paulus, A.; Cohen, A. S.; Guttman, A.; Karger, B. L. J. Chromatogr. 1989, 480, $111-127$. 